\title{
Prenatal micronutrient supplementation: Are we there yet?
}

\author{
Zulfiqar A. Bhutta MBBS PhD, Batool Azra Haider MBBS MSc
}

$\infty \infty$

See related research paper by Shah and colleagues, page E99

$\mathrm{M}$ aternal undernutrition is one of most neglected aspects of nutrition in public health globally. Although relatively few indicators are systematically tracked or reported, a recent review of the global burden of maternal undernutrition concluded, despite limited information, that some $10 \%-19 \%$ of women of reproductive age were seriously undernourished. With a body mass index (BMI) of less than 18.5, these women were at increased risk of delivering low-birth-weight infants. ${ }^{1}$ A significant proportion of women of reproductive age also have deficient levels of micronutrients. ${ }^{2}$ In the developed world, deficiencies in micronutrients may be associated with low maternal age, poverty and poor diets or food faddism. In much of the developing world, such deficiencies are also compounded by high fertility rates, repeated pregnancies and short intervals between pregnancies.

Information on the range and scale of micronutrient deficiencies among women of reproductive age is limited. Although iron-deficiency anemia is recognized as an important risk factor for maternal and perinatal mortality globally, ${ }^{3}$ the contribution of other micronutrient deficiencies to adverse outcomes of pregnancy is less clear. However, emerging evidence suggests that micronutrients such as vitamin $B_{12}$ and folic acid, ${ }^{4}$ vitamin $\mathrm{D}^{5}$ and selenium ${ }^{6}$ may also be important for maternal, infant and child outcomes. It is thus logical to assume that, in poor populations with a high burden of disease, women of reproductive age may be malnourished, and have a low BMI, short stature and frequently subclinical deficiencies in multiple micronutrients.

In this issue of CMAJ (page 1200), Shah and Ohlsson, representing the Knowledge Synthesis Group on Determinants of Low Birth Weight and Preterm Births, present the findings from their systematic review of the effect of supplementation with multiple micronutrients on pregnancy outcomes, including birth weight and the prevalence of low-birth-weight infants and preterm births. From their meta-analysis of 13 published trials, they conclude that supplementation with multiple micronutrients, compared with iron and folate supplements only, was associated with a 17\%-19\% reduction in the risk of low birth weight; they also found an increase in the mean birth weight of $54 \mathrm{~g}$ (95\% confidence interval $36 \mathrm{~g}-72 \mathrm{~g}$ ).

Limitations of their review should be considered before accepting these conclusions as definitive evidence of impact. Several recent studies included in the meta-analysis were cluster-randomized trials, and at least one was an effectiveness trial. Arguably, Shah and Ohlsson should have adjusted

\section{Key points}

- Deficiencies in micronutrients affect many women of reproductive age and are associated with adverse maternal and perinatal outcomes.

- Micronutrients that may be important for maternal, infant and child outcomes include iron, vitamin $\mathrm{B}_{12}$, folic acid, vita$\min \mathrm{D}$ and selenium.

- In addition to multimicronutrient supplementation, optimal interventions to improve maternal nutrition need to address household food insecurity and reduce the burden of maternal infections such as HIV infection and malaria.

- If proven effective and safe in representative health care systems, supplementation with multimicronutrients should replace supplementation with iron and folic acid in susceptible populations.

the meta-analysis for the possible design effect of these cluster-randomized trials. ${ }^{8}$ They also did not perform a disaggregated analysis by maternal nutritional status or stature, which could indicate whether the reported outcomes and benefits were consistent across all categories.

Shah and Ohlsson do not report outcomes beyond nutritional status at birth. The benefits of interventions to improve maternal nutrition, especially micronutrient supplementation, may well accrue well after the newborn period. Indeed, benefits on improved survival ${ }^{9}$ and growth in infancy and childhood $^{10}$ have been reported. More critically, the authors report a limited repertoire of outcomes, omitting perinatal and neonatal mortality and important morbidity outcomes. Such outcomes are relevant given the considerable controversy surrounding a reported increased risk of neonatal mortality following supplementation with multiple micronutrients during pregnancy. ${ }^{11}$ If increased body size, especially head size, may be a consequence of such supplementation, then provision of adequate skilled care and referral services in childbirth are important prerequisites before the large-scale provision of multiple micronutrients to replace iron and folate supplements in malnourished populations can be recommended.

Notwithstanding the above considerations, appropriate strategies for the prevention and management of maternal undernutrition and micronutrient deficiencies in developing countries are a priority. However, these strategies may require multiple interventions. Evidence-based interventions that can

From the Division of Maternal and Child Health, Department of Paediatrics and Child Health, The Aga Khan University, Karachi, Pakistan 
improve maternal nutritional status and fetal growth include fortified food supplements or conditional cash transfers to address household food insecurity, micronutrient interventions that address iron-deficiency anemia and other deficiencies, and measures to reduce the burden of maternal infections such as HIV infection, malaria and helminthiasis. ${ }^{12}$ In a recent evaluation of the benefits of administering multivitamins and deworming among pregnant women with severe anemia, an enhanced regimen with mebendazole therapy and multivitamin supplementation was found to have a modest benefit over the standard treatment of daily supplementation with iron and folic acid only. ${ }^{13}$ Thus, optimal maternal nutrition should be achieved through multiple interventions supported and promoted by different delivery strategies, rather than micronutrient supplementation alone.

At the Copenhagen Consensus 2008, micronutrient supplementation and fortification were identified as among the most cost-effective interventions to address infant and child undernutrition globally, with benefit-cost ratios of 9.5-17.3 (estimated annual gains of $\$ 3.7$ billion for net investments of $\$ 346.4$ million). ${ }^{14}$ However, other than iron fortification, the group identified no strategies for addressing the size of the problem among women of reproductive age.

Additional strategies clearly need to find their way into public health programs. Given the success of 2 recent largescale projects for multimicronutrient supplementation in Indonesia ${ }^{9}$ and China, ${ }^{15}$ further system-wide projects need to be undertaken, with careful surveillance of perinatal mortality. If proven effective and safe in representative health care systems, multimicronutrient supplementation should replace iron-folic acid supplementation in susceptible populations.

This article has been peer reviewed.

Competing interests: None declared.

Contributors: Both of the authors were involved in the drafting and revision of this manuscript and approved the final version submitted for publication.

\section{REFERENCES}

1. Black RE, Allen LH, Bhutta ZA, et al.; Maternal and Child Undernutrition Study Group. Maternal and child undernutrition: global and regional exposures and health consequences. Lancet 2008;371:243-60.

2. Allen LH. Multiple micronutrients in pregnancy and lactation: an overview. Am J Clin Nutr 2005;81:1206S-12S.

3. Stoltzfus RJ. Iron deficiency: global prevalence and consequences. Food Nutr Bull 2003;24(Suppl 4):S99-103

4. de Benoist B. Conclusions of a WHO technical consultation on folate and vitamin $\mathrm{B}_{12}$ deficiencies. Food Nutr Bull 2008;29(Suppl 2):S238-44.

5. Kovacs CS. Vitamin D in pregnancy and lactation: maternal, fetal, and neonatal outcomes from human and animal studies. Am J Clin Nutr 2008;88:520S-8S.

6. Kupka R, Mugusi F, Aboud S, et al. Randomized, double-blind, placebo-controlled trial of selenium supplements among HIV-infected pregnant women in Tanzania: effects on maternal and child outcomes. Am J Clin Nutr 2008;87:1802-8.

7. Shah PS, Ohlsson A; Knowledge Synthesis Group on Determinants of Low Birth Weight and Preterm Births. Effects of prenatal multimicronutrient supplementation on pregnancy outcomes: a meta-analysis. CMAJ 2009;180:1200-6.

8. White IR, Thomas J. Standardized mean differences in individually-randomized and cluster-randomized trials, with applications to meta-analysis. Clin Trials 2005; 2:141-51
9. Shankar AH, Jahari AB, Sebayang SK, et al; Supplementation with Multiple Micronutrients Intervention Trial (SUMMIT) Study Group. Effect of maternal multiple micronutrient supplementation on fetal loss and infant death in Indonesia: a double-blind cluster-randomised trial. Lancet 2008;371:215-27.

10. Vaidya A, Saville N, Shrestha BP, et al. Effects of antenatal multiple micronutrient supplementation on children's weight and size at 2 years of age in Nepal: followup of a double-blind randomized controlled trial. Lancet 2008;371:492-9.

11. Christian P, Osrin D, Manandhar DS, et al. Antenatal micronutrient supplements in Nepal. Lancet 2005;366:711-2.

12. Bhutta ZA, Ahmed T, Black RE, et al.; Maternal and Child Undernutrition Study Group. What works? Interventions for maternal and child undernutrition and survival. Lancet 2008;371:417-40.

13. Christian P, Shahid F, Rizvi A, et al. Treatment response to standard of care for severe anemia in pregnant women and effect of multivitamins and enhanced anthelminthics. Am J Clin Nutr 2009;89:853-61.

14. Horton S, Alderman H, Rivera JA. Hunger and malnutrition [Copenhagen Consensus 2008 challenge paper]. Copenhagen (Denmark): Copenhagen Consensus Center; 2008. Available: www.copenhagenconsensus.com/Default.aspx?ID=1149 (accessed 2009 May 1).

15. Zeng L, Dibley MJ, Cheng Y, et al. Impact of micronutrient supplementation during pregnancy on birth weight, duration of gestation, and perinatal mortality in rural western China: double blind cluster randomised controlled trial. BMJ 2008;337:a2001.

Correspondence to: Dr. Zulfiqar A. Bhutta, Husein Lalji Dewraj

Professor and Head, Division of Maternal and Child Health,

The Aga Khan University, Stadium Road, Karachi 74800,

Pakistan; zulfiqar.bhutta@aku.edu

\section{Special launch promotion}

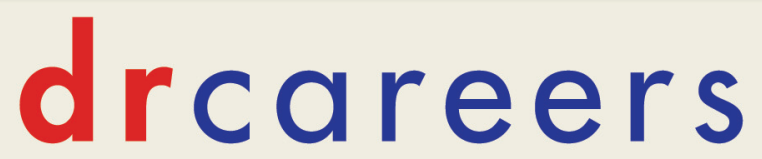

\section{$\mathrm{CMA}^{\prime}$ s career centre for physicians}

\section{Helping employers find the right physicians. Fast.}

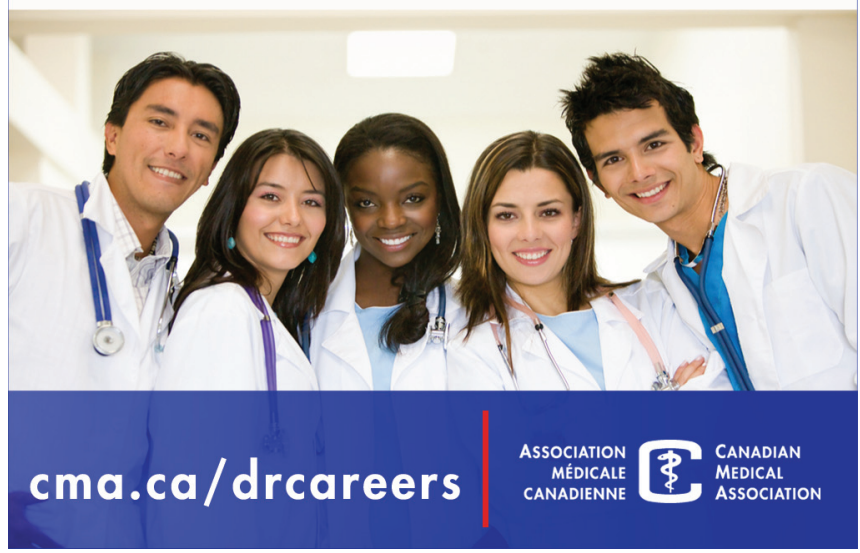

